\title{
Post-traumatic stress disorder among former Islamic State child soldiers in northern Iraq
}

Jan Ilhan Kizilhan and Michael Noll-Hussong

\section{Background}

Former child soldiers are at high risk of developing mental disorders such as post-traumatic stress disorder (PTSD); however, their comprehensive mental health has yet to be examined.

\begin{abstract}
Aims
This study looks at the prevalence of PTSD, depression and associated risk factors such as disturbed self-esteem among
\end{abstract} former child soldiers of the so-called 'Islamic State'.

\section{Method}

The psychological effect of traumatic events was assessed in 81 Yazidi children who had been child soldiers for the Islamic State in northern Iraq between 2014 and 2017 for at least 6 months. The children were between 8 and 14 years of age. Thirty-two Yazidi boys and 31 Muslim boys who were not child soldiers in Iraq served as control groups. A structured psychological interview and established psychometric questionnaires were used to assess traumatisation and mental disorders.

\section{Results}

The child soldiers showed a significantly higher prevalence of PTSD (48.3\%), depressive disorders (45.6\%), anxiety disorders $(45.8 \%)$ and somatic disturbances (50.6\%) than the boys who had not been child soldiers. Developmentally crucial self-esteem was significantly reduced in former child soldiers. No significant differences between the two control groups could be found.

\section{Conclusions}

PTSD and other mental disorders are highly present among former child soldiers in northern Iraq. The study highlights the huge and as yet unmet need for psychological services among former child soldiers.

\section{Declaration of interest \\ None.}

\section{Keywords}

Post-traumatic stress disorder; Yazidi; abuse; abuse history; terrorism; child soldiers; mental disorder; mental health.

\section{Copyright and usage}

(c) The Royal College of Psychiatrists 2018.
Every day, thousands of children worldwide are forced to serve as soldiers in armed conflicts, becoming the recipients and perpetrators of violence and thus experiencing a great number of atrocities. It has been officially estimated by the United Nations Children's Emergency Fund that about 300000 children younger than 18 years of age are currently serving as soldiers, guerrilla fighters or in support roles in more than 50 countries around the world. ${ }^{1}$ These minors undertake a variety of roles, including acting as spies, porters and front-line soldiers, and are often involved in the exertion of extraordinary violence toward others as well as being subjected to repeated physical, sexual and emotional violence. Thus, former child soldiers are at high risk of developing mental disorders like post-traumatic stress disorder (PTSD)., ${ }^{2,3}$

In August 2014, when troops of the self-proclaimed 'Islamic State' conquered areas of northern Iraq, they turned on the long-established religious minorities in the area with tremendous brutality, especially the Yazidis. ${ }^{4}$ Vast numbers of men were executed, and women and children were abducted and wilfully subjected to sexual violence. ${ }^{5}$

From the beginning, the Islamic State deliberately targeted boys aged between 8 and 14 years old, tearing them away from their families and training and indoctrinating them as child soldiers, ${ }^{5,6}$ often by means of daily religious indoctrination and martial arts to achieve dehumanised indifference to pain, brutality and terror. ${ }^{7}$ Nevertheless, some of these young Yazidis managed to flee captivity or have been freed in return for a ransom payment. These former child soldiers now live near Duhok and Zakho in northern Iraq in approximately 24 refugee camps, each housing up to 28000 refugees. Treatment options within these camps are severely limited or non-existent. ${ }^{8,9}$

Previous research such as that in northern Uganda, Palestine or Rwanda revealed high rates of post-traumatic reactions among children who had been abducted as child soldiers. ${ }^{10-13}$ Nasiroglu and $\mathrm{Ceri}^{7}$ interviewed children and adolescents in a refugee camp in Turkey approximately 2 years after the 2014 Islamic State attack in Iraq, and concluded that $43 \%$ of the survivors showed moderate to severe post-traumatic stress reactions. Post-traumatic stress reactions in children and young adolescents were associated with parental loss, exposure to violence and, most importantly, the feeling that their life was perpetually in danger. In the study mentioned, there is no information about child soldiers and their mental health situation. Until now, there has been a paucity of studies specifically comparing the mental health status of former child soldiers with that of children living through war without being recruited into armed groups. Thus, Kohrt et al. ${ }^{14}$ compared differently exposed groups in Nepal and reported greater severity of mental health problems in former child soldiers compared with children never conscripted by armed groups, after controlling for trauma exposure. However, it is not yet clear what aspects of the child soldier experience contribute to the poorer mental health outcomes in this population. ${ }^{14,15}$ Specifically, the extent to which this difference may be related to the effect of other experiences on children's psychosocial well-being, such as sexual violence, is still unknown.

Moreover, research suggests that trauma events can also be followed by lowered self-esteem in children, ${ }^{16}$ which can affect the mental health and the (development of) personality over the long term. ${ }^{17}$ Many studies have demonstrated an association between violence or abuse and low self-esteem in children. ${ }^{18,19}$

Against this background, Freh $^{16}$ noted that children's exposure to war-related trauma varies greatly as a function of context and other individual factors, such as gender or ethnicity. Last but not least, given that effective intervention strategies need to be culturally sensitive and respectful of the social ecology, it is of special importance to report on the mental health of former child soldiers misused by the Islamic State in Iraq in comparison with children who were 
never directly abducted by the Islamic State, to address the specific problems faced by this most sensitive war-affected population.

Altogether, there have been no studies done so far that focus specifically on the psychological burden on Iraqi child soldiers. Although it might be intuitive that war and widespread violence leave deep bio-psychosocial scars, it is essential to further our understanding of the mental health effect these scars have on children. The relevance of the topic is striking at a medical, developmental and humanitarian level, as lost childhood can take years to recover from and physical and psychological trauma may be long lasting. ${ }^{6-8}$

\section{Method}

The study was led by the Institute of Psychotherapy and Psychotraumatology at the University of Duhok in Iraq. The study was approved by the University Ethical Review Board and Health Directorate in Duhok, Iraq, and performed in accordance with the Declaration of Helsinki. We confirm that all the research meets ethical guidelines, including adherence to the legal requirements of the country in the study. Written informed consent was obtained from the patients for publication of this article and any accompanying information.

\section{Sample}

The former child soldiers (group one) were Yazidi boys aged between 8 and 14 years $(n=81$; mean 12.61 , s.d. 2.61) from the area of Sinjar in northern Iraq. They were held captive between August 2014 and May 2017 for at least 3 months by the Islamic State in Iraq and Syria. The first control group ( $n=32$; mean 12.24, s.d. 2.46; group two) met the following criteria: they were Yazidi boys who came from the same region and were living in refugee camps, but did not serve as child soldiers. The second control group ( $n=31$; mean 12.89, s.d. 2.96; group three) met the following criteria: they were Muslim boys who came from the same region and were living in refugee camps, but did not serve as child soldiers. At the time of the investigation, all participants were living in refugee camps near the city of Dohuk in northern Iraq.

The first author (J.I.K.) got in touch with both the investigational and the control group through licensed physicians and psychologists in the refugee camps who he knew from earlier joint projects. Before the actual data collection, a first visit was made to the participants' housing with the following aims: to provide the adolescents and their families/legal guardians with a description of the study and its purpose, and to tell them how the anonymised data would be used, to ensure informed consent and to obtain written permission for their participation in the study. It is of note that everyone (children and guardians) who had been asked to participate in the study and/or give approval agreed to do so and completed the full procedure detailed below. The interviews were done verbally with 194 male individuals and the investigators promptly transcribed the answers according to the chosen instruments. Not all interviewees filled in the complete questionnaire $(n=113,58.2 \%)$ and after elimination of the incomplete data-sets, there remained a sample of 81 interviewees $(41.8 \%)$ for analysis. Each interview lasted approximately $60 \mathrm{~min}$ on average.

All participants were examined within a time period of 3 days before the interview by a licensed physician from the refugee camps, and none had any clinically relevant medical findings or records. The data collection was carried out by trained professionals from 1 July to 15 October 2017, with continuous supervision by J.I.K.

\section{Measures}

The Children's DIPS ${ }^{20}$ is the children's version of the 'Diagnostic Interviews for Mental Disorders'. ${ }^{21,22}$ It is the extended version of the 'Anxiety Disorders Schedule - Revised'. ${ }^{23}$ This interview is a structured one in which the nature and order of the questions as well as the coding and the evaluation of answers are predefined, in accordance with the SCID (Structured Clinical Interview for DSM-IV) system for adults. The interviewer may, however, put further questions to remove ambiguity, for example, if they feel that there is a question the younger interviewee does not understand. The Children's DIPS allows for the diagnosis of lifetime and point prevalence of mental disorders on the basis of both the criteria of the DSM-IV and the investigation criteria of the ICD- $10 .^{21}$ It is earmarked for children and juveniles aged 6-18 years. Interrater and test-retest reliabilities are rated as satisfactory by the test authors.

The questionnaire was translated from its German version into Arabic and then re-translated and checked by an Arabic-speaking physician and psychologist in Germany. Systematic validity or reliability studies have not been carried out so far.

The Event Scale, adapted by Dyregrov and Yule ${ }^{24}$ for the situation in Iraq, is a 15-item questionnaire designed to assess the nature and extent of exposure to various war events. The answers reflect whether the event occurred before, during or after captivity (multiple answers are possible) and whether the respondent only witnessed the event or personally experienced it.

The Child PTSD Reaction Index (Arabized Version) is a translation of the Child PTSD Reaction Index (CPTSD-RI) developed by Frederic et al. ${ }^{25}$ It consists of a 20 -item self-report (interview format) questionnaire based on DSM-IV criteria for PTSD. Items are rated on a five-point Likert scale ranging from 0 (never) to 4 (most of the time). CPTSD-RI score ranges and corresponding degrees of PTSD symptom severity are as follows: 0-11, none; 12-24, mild; 25-39, moderate; 40-59, severe and $60-80$, very severe. The CPTSD-RI total scale displayed good to excellent internal consistency, and reliability across age ranges, gender and racial/ethnic groups. ${ }^{15,26}$ Thus, the Arabized instrument has been previously used with Palestinian children and was found to be appropriate for this population. ${ }^{27}$ The CPTSD-RI total scale displayed good to excellent internal consistency, and reliability across age ranges, gender and racial/ethnic groups $(\alpha=0.78-0.88) .^{27}$

The Arabized Version of the Children's Depression Inventory consists of 27 items related to depression symptoms, measured on a three-point scale (always, sometimes or never). It is based on the original instrument developed by Kovacs. ${ }^{28}$ Reliability and validity of the Arabized version have been shown to be comparable with the original instrument. ${ }^{29}$ Reliability and validity of the Arabized version have also been shown to be comparable with the original instrument $(\alpha=0.86){ }^{29,30}$

The Coopersmith Self-Esteem Inventory ${ }^{31}$ is a 25 -item scale that was translated, Arabized, normed and validated on Arab children by Musa and Dassouki. ${ }^{32}$ The instrument has been used widely on Arab children, including Palestinians, and was found to be appropriate for such populations $(\alpha=0.92){ }^{31}$

\section{Statistical analyses}

The data were analysed with SPSS (IBM, New York, USA), version 11.0 for Microsoft Windows. The data were scored, coded and analysed with descriptive statistics and discriminant analysis on the scores of the three groups of children according to age, gender, PTSD, depression and self-esteem. A critical statistical significance was determined for an overall effect at $\alpha=0.05$. Given the size of the survey sample, statistical analyses were carried out with non-parametric statistical methods. The multiple comparisons of the groups were undertaken by means of the Mann-Whitney $\mathrm{U}$ test, considering the statistical significance adjusted according to Bonferroni. 


\begin{tabular}{|c|c|c|c|c|c|c|}
\hline & \multicolumn{2}{|c|}{$\begin{array}{l}\text { Yazidi child soldiers, } n= \\
81 \text { (group one) }\end{array}$} & \multicolumn{2}{|c|}{$\begin{array}{l}\text { Yazidi boys who were not } \\
\text { child soldiers, } n=32 \\
\text { (group two) }\end{array}$} & \multicolumn{2}{|c|}{$\begin{array}{l}\text { Muslim boys who were not } \\
\text { child soldiers, } n=31 \text { (group } \\
\text { three) }\end{array}$} \\
\hline & Mean & s.d. & Mean & s.d. & Mean & s.d. \\
\hline Age & 12.2 & 2.61 & 12.1 & 2.12 & 12.4 & 2.16 \\
\hline No. of siblings & 5.8 & 3.51 & 5.4 & 3.23 & 5.2 & 3.12 \\
\hline \multirow[t]{2}{*}{ School attendance (in years) } & 5.0 & 0.90 & 5.2 & 1.20 & 5.8 & 1.50 \\
\hline & $N$ & $\%$ & $N$ & $\%$ & $N$ & $\%$ \\
\hline \multicolumn{7}{|l|}{ Father's profession } \\
\hline Farmer & 40 & 49.4 & 13 & 40.6 & 12 & 36.4 \\
\hline Skilled worker & 18 & 22.2 & 10 & 31.3 & 11 & 33.3 \\
\hline Civil employee/unemployed & 10 & 12.3 & 5 & 15.6 & 5 & 15.2 \\
\hline Freelancer/self-employed & 11 & 13.6 & 3 & 9.4 & 3 & 9.1 \\
\hline Retired & 6 & 7.4 & 1 & 3.1 & 2 & 6.1 \\
\hline
\end{tabular}

\section{Results}

\section{Demographics}

Table 1 shows the sociodemographic data of the three groups. The final sample consisted of 81 child soldiers with a mean age of 12.2 (range 8-14; s.d. 2.61) years; 32 Yazidi boys who were not child soldiers, with a mean age of 12.1 (range 9-14; s.d. 2.12) years; and 31 Muslim boys who were not child soldiers, from the same area with a mean age of 12.4 (range $8-14$; s.d. 2.16) years.

With regard to their guardians and employment (income US $\$ 800-1000), 40$ fathers (49.4\%) described themselves as farmers (income US\$600-800), 18 (22.2\%) were skilled workers (income US\$600-800), 11 (13.6\%) were freelancers or self-employed (income US\$800-1200), ten (12.3\%) were civil service employees or unemployed (income US\$800-1200) and six (7.4\%) were retired (income US\$400-600). There are no significant differences between the groups (Table 1 ).

In the past 20 years, the interviewed participants (selected boys and their parents/guardians) had not been involved in any war action, flight, captivity and/or organised use of force/violence until the attack by the Islamic State in 2014 .

\section{Events}

As expected, the self-reported exposure to traumatic events was very high. On the Event Scale, all participants showed that they had experienced some kind of violence, had been exposed to threatening events, had been raped and/or had lost family members during the Islamic State attack or captivity. About $81 \%$ of the boys had seen dead or mutilated bodies or had been the victim of an attack or looting (100\%).

Many participants had witnessed someone being brutally killed (47\%), had witnessed the death of family members (cousins, aunts, uncles, etc.) (37\%) or had lost siblings (90\%). The child soldiers reported that they had injured someone with a weapon (15\%). The mean total score on the Event Scale for the whole sample was 12.6 out of a maximum of 15 (s.d. 2.9; median 13; range 11-15).

\section{Psychological disorders}

All child soldiers remembered the day of the beginning of their captivity as being extremely frightening and traumatising. Over $78 \%$ of the boys described feelings of intense fear, helplessness, horror and severe pain, and over $74 \%$ were still suffering from intrusive reexperiences of their captivity. For $68 \%$ of the participants, the event was unexpected and without any preliminary or non-integrable explanation.

Table 2 shows that almost $45.6 \%$ of the child soldiers met the criteria for an anxiety disorder. A total of $14.8 \%$ were suspected of suffering from disorders of their developing personality and $49.3 \%$ met the criteria for a somatoform disorder. In addition, $50.6 \%$ of the child soldiers complained of a range of unspecific somatic problems. In the Yazidi control group, $31.2 \%$ met the criteria for a somatoform disorder, and $12(37.5 \%)$ boys fulfilled the criteria for an anxiety disorder. Two met the criteria for a personality disorder (6.3\%). Fourteen (43.8\%) boys from the control group complained of somatic disturbances (Table 2).

\section{PTSD symptoms}

The mean PTSD score for group one (48.3) falls within the high PTSD symptom score range (32-67) (Table 3). The two control groups (group two 14.5; group three 14.2) fell within the low PTSD symptom score range (12-25). The scores, however, varied widely among the two control groups, ranging from experiences of mild $(0-18)$ to very severe symptoms $(>28)$. The child soldiers in group one had a significantly higher PTSD symptom score range $(P<0.001)$.

The mean depression scores depicted in Table 3 reveal that group one displayed moderate (45th-54th percentile) symptoms

\begin{tabular}{|c|c|c|c|c|c|c|c|c|}
\hline \multirow[t]{2}{*}{ ICD-10 diagnosis/somatic symptoms } & \multicolumn{2}{|c|}{$\begin{array}{l}\text { Yazidi child } \\
\text { soldiers, } n=81 \\
\end{array}$} & \multicolumn{2}{|c|}{$\begin{array}{l}\text { Yazidi boys } \\
\text { who were not } \\
\text { child soldiers, } \\
n=32 \\
\end{array}$} & \multicolumn{2}{|c|}{$\begin{array}{l}\text { Muslim boys } \\
\text { who were not } \\
\text { child soldiers, } \\
n=31\end{array}$} & \multirow[t]{2}{*}{$P$ Value } & \\
\hline & $N$ & $\%$ & $N$ & $\%$ & $N$ & $\%$ & & \\
\hline Anxiety disorders (F40-41) & 37 & 45.8 & 11 & 34.4 & 10 & 32.2 & 1.55 & 0.16 \\
\hline Somatoform disorders (F45) & 40 & 49.3 & 9 & 28.2 & 8 & 25.8 & 1.65 & 0.32 \\
\hline Personality disorders (F60) & 12 & 14.8 & 2 & 6.3 & 3 & 9.7 & 0.78 & 0.21 \\
\hline $\begin{array}{l}\text { Somatic disturbance (stomach ache, regurgitation, } \\
\text { headache, circulatory disturbance, etc.) }\end{array}$ & 41 & 50.6 & 10 & 31.2 & 10 & 32.3 & 0.80 & 0.24 \\
\hline
\end{tabular}




\begin{tabular}{|c|c|c|c|}
\hline Variable & PTSD $^{a}$ & Depression $^{\mathrm{b}}$ & Self-esteem ${ }^{c}$ \\
\hline \multicolumn{4}{|c|}{ Group one: Yazidi child soldiers $(n=81)$} \\
\hline Mean & 48.3 & 36.57 & 24.61 \\
\hline s.d. & 13.73 & 4.6 & 3.17 \\
\hline Range & $32-67$ & 23-38 & $18-26$ \\
\hline \multicolumn{4}{|c|}{ Group two: Yazidi boys who were not child soldiers $(n=30)$} \\
\hline Mean & 14.50 & 16.07 & 9.1 \\
\hline s.d. & 10.48 & 5.45 & 2.65 \\
\hline Range & $0-18$ & $0-18$ & $0-11$ \\
\hline \multicolumn{4}{|c|}{ Group three: Muslim boys who were not child soldiers $(n=31)$} \\
\hline Mean & 14.12 & 15.09 & 8.42 \\
\hline s.d. & 9.52 & 5.41 & 2.81 \\
\hline Range & $0-16$ & $0-16$ & $0-9$ \\
\hline \multicolumn{4}{|c|}{$\begin{array}{l}\text { Means, s.d. and ranges of post-traumatic stress disorder (PTSD), depression and self- } \\
\text { esteem scores distributed according to group membership. } \\
\text { a Theoretical range } 0-80 \text {. } \\
\text { b Theoretical range } 0-54 \text {. } \\
\text { c Theoretical range } 0-25 \text {. }\end{array}$} \\
\hline
\end{tabular}

of depression. Groups two and three displayed minor (0-18th percentile) symptoms of depression. Table 3 , however, also shows that child soldiers (group one) displayed depression scores significantly $(P<0.001)$ higher (mean 36.57) than the Yazidi (mean 16.07) or Muslim boys who had not been child soldiers (mean 15.09). The dispersion of depression scores was particularly pronounced in group two (range 0-18) compared with group three (range 0-16) and group one (range 23-38).

The results depicting self-esteem scores show that the mean values of group one (24.61) fall outside the norms for their peers in the Arabic-speaking world. ${ }^{27}$ Group two (9.1) and group three (8.42) scored inside the norms (fifth stanine). There is a significant difference between group one and groups two and three $(P<0.001)$. Groups two and three did not differ from each other significantly, as shown in Table 4.

The results of the discriminant analysis revealed that PTSD $(P<$ $0.001)$, depression $(P<0.001)$ and self-esteem $(P<0.001)$ scores were variably capable of discriminating between the three groups with statistical significance.

\section{Discussion}

This study looks at the prevalence of PTSD, depressed mood and associated risk factors like altered self-esteem among former child soldiers of the Islamic State. The results of this study indicate that the experience of being a child soldier is likely to cause various psychological disturbances, leading to mental disorders, especially PTSD. The high rate of PTSD of more than $48.3 \%$ in the investigated group is comparable with the rate of PTSD in child soldiers in other countries such as Rwanda, Uganda or Sudan, which on average ranges from 30 to $67 \%{ }^{3,33,34}$ Altogether, symptoms of depression, psychosomatic conditions, sleep disturbances and PTSD were found to be above normal levels. These findings are likewise congruent with previous findings in studies on child soldiers. ${ }^{35,36}$ The

Table $4 F$ values for education, age, post-traumatic stress disorder (PSTD), depression and self-esteem means according to group membership.

$\begin{array}{lcl}\text { Variable } & \text { F Statistic } & P \text { Value } \\ \text { Education (school in years) } & 0.037 & \text { Not significant } \\ \text { Age } & 0.476 & \text { Not significant } \\ \text { PTSD } & 9.704 & P<0.001 \\ \text { Depression } & 7.303 & P<0.001 \\ \text { Self-esteem } & 8.108 & P<0.001\end{array}$

results of the study also showed that symptoms of depression and low self-esteem can constitute an index capable of discriminating between the three groups with statistical significance.

Despite the fact that warlike situations and human rights violations as 'anthropological constants' have existed over the centuries, especially against religion minorities such as the Yazidis in Iraq, the results imply that even the embedment of societies does not comprehensively protect against the development of PTSD and other mental disorders. ${ }^{37}$

Although the results of this study suggest that being a child soldier in a terrorist organisation like the Islamic State exerts a major negative effect on mental health beyond somatic complications, some caution is warranted in the interpretation of these results. This could, on the one hand, be ascribed to the fact that the circumstances in which these children had to survive are traumatising in themselves, and it is difficult to distinguish the effects of different types of trauma on the development of mental and especially post-traumatic stress symptoms or disorders. Moreover, the effect of a trauma is always linked to the subjective attribution of the events and to the historical-cultural, social and political contexts. $^{38,39}$

Last but not least, the alarmingly high rates of psychiatric disturbances among the child soldiers provide striking evidence that researchers and clinicians, as well as policy makers, have an ethical obligation to pay more attention to the urgent needs of child soldiers as the most sensitive and often neglected members of our societies. Comprehensive psychosocial rehabilitation beyond the provision of education and vocational training, including psychological therapy, should therefore form the basis of resettlement and re-integration according to the United Nations Convention on the Rights of the Child. It has to be stressed that treating child soldiers with PTSD who are from traditionally family- or collective-oriented societies like the Yazidis requires a different, culturally sensitive approach and adapted skills for an effective and specifically psychotherapeutic treatment. ${ }^{40,41}$

Moreover, a special multidisciplinary long-term concept with teachers, social workers and therapists is needed to effectively reintegrate the child soldiers into society.

Finally, the presence of mental health problems among neverconscripted children illustrates the need for comprehensive, postconflict community-based psychosocial care not restricted only to child soldiers. The long-lasting effects of childhood traumatisation needs further examination. ${ }^{40,41}$

\section{Limitations}

The Children's DIPS was translated from its German version into Arabic and then re-translated and checked by an Arabic-speaking physician and psychologist in Germany. This limits the explanatory power of the study. The group size of participants presents an important limitation of the study and the results do not allow for general conclusions about the prevalence of mental disorders in child soldiers. The composition characteristics of the groups (i.e. their low age and level of education) might also have had an influence on our findings.

Jan Ilhan Kizilhan, PhD, Institute for Psychotherapy and Psychotraumatology, University of Duhok, Iraq and State University Baden-Württemberg, Germany; Michael Noll-Hussong, MD, Clinic for Psychiatry and Psychotherapy, Division of Psychosomatic Medicine and Psychotherapy, Universitaetskliniken des Saarlandes, Germany

Correspondence: Jan Ilhan Kizilhan, PhD, State University Baden-Württemberg, Friedrich-Ebert-Strasse 30, D-78054 Villingen-Schwenningen, Germany. Email: Jan. Kizilhan@dhbw-vs.de

First received 5 Mar 2018, final revision 4 Apr 2018, accepted 8 Apr 2018 


\section{References}

1 The United Nations Children Fund (UNICEF). More than 1 in 10 Children Living in Countries and Areas Affected by Armed Conflict. UNICEF USA, 29 Jan. 2015.

2 Betancourt TS, Brennan RT, Rubin-Smith J, Fitzmaurice GM, Gilman SE. Sierra Leone's former child soldiers: a longitudinal study of risk, protective factors, and mental health. J Am Acad Child Adolesc Psychiatry 2010; 49: 606-15.

3 Derluyn I, Broekaert E, Schuyten G, De Temmerman E. Post-traumatic stress in former Ugandan child soldiers. Lancet 2004; 363: 861-3.

4 Cetorelli V, Sasson I, Shabila N, Burnham G. Mortality and kidnapping estimates for the Yazidi population in the area of Mount Sinjar, Iraq, in August 2014: a retrospective household survey. PLOS Med 2017; 14: e1002297.

5 Kelly JT, Branham L, Decker MR. Abducted children and youth in Lord's Resistance Army in Northeastern Democratic Republic of the Congo (DRC): mechanisms of indoctrination and control. Confl Health 2016; 10: 11.

6 Gerdau I, Kizilhan Jl, Noll-Hussong M. Posttraumatic Stress Disorder and Related Disorders among Female Yazidi Refugees following Islamic State of Iraq and Syria Attacks-A Case Series and Mini-Review. Front Psychiatry 2017; 8: 282

7 Nasiroglu S, Ceri V. Posttraumatic stress and depression in Yazidi refugees. Neuropsychiatr Dis Treat 2016; 12: 2941-8.

8 Ceri V, Ozlu-Erkilic Z, Ozer U, Yalcin M, Popow C, Akkaya-Kalayci T. Psychiatric symptoms and disorders among Yazidi children and adolescents immediately after forced migration following ISIS attacks. Neuropsychiatr 2016: 30: 145-50.

9 Tekin A, Karadag H, Suleymanoglu M, Tekin M, Kayran Y, Alpak G, et al. Prevalence and gender differences in symptomatology of posttraumatic stress disorder and depression among Iraqi Yazidis displaced into Turkey. Eur Psychotraumatol 2016; 7: 28556.

10 Dyregrov A, Gupta L, Gjestad R, Mukanoheli E. Trauma exposure and psychological reactions to genocide among Rwandan children. J Trauma Stress 2000; 13: 3-21.

11 Kizilhan Jl. Behandlung traumatisierter Frauen in Deutschland. Forens Psychiatr Psychol Kriminol 2017; 11: 335-41.

12 Mohammadi D. Help for Yazidi survivors of sexual violence. Lancet Psychiatry 2016; 3: 409-10

13 Moscardino U, Scrimin S, Cadei F, Altoe G. Mental health among former child soldiers and never-abducted children in northern Uganda. Scientific World Journal 2012: 2012: 367545.

14 Kohrt BA, Jordans MJ, Tol WA, Speckman RA, Maharjan SM, Worthman CM, et al. Comparison of mental health between former child soldiers and children never conscripted by armed groups in Nepal. JAMA 2008; 300: 691-702.

15 Thabet AA, Vostanis P. Post traumatic stress disorder reactions in children of war: a longitudinal study. Child Abuse Neg/ 2000; 24: 291-8.

16 Freh FM. Psychological effects of war and violence on children. J Psychol Abnormalities 2016; 5: 1-2.

17 Lee A, Hankin BL. Insecure attachment, dysfunctional attitudes, and low selfesteem predicting prospective symptoms of depression and anxiety during adolescence. J Clin Child Adolesc Psychol 2009; 38: 219-31.

18 Turner HA, Finkelhor D, Ormrod R. The effects of adolescent victimization on self-concept and depressive symptoms. Child Maltreat 2010; 15: 76-90.

19 Young JC, Widom CS. Long-term effects of child abuse and neglect on emotion processing in adulthood. Child Abuse Neg/ 2014; 38: 1369-81.

20 Unnewehr S, Schneider S, Margraf J. Kinder-DIPS: Diagnostisches Interview be psychischen Störungen im Kindes- und Jugendalter. Springer Berlin Heidelberg 2013.
21 Margraf J, Schneider S, Ehlers A, DiNardo P, Barlow D. DIPS Diagnostisches Interview bei psychischen Störungen: Interviewleitfaden. Springer Berlin Heidelberg, 2013

22 Margraf J, Schneider S, Ehlers A, Psychologie C-D-SfK. Diagnostisches Interview bei psychischen Störungen: DIPS: Springer, 1991

23 Di Nardo PA, Barlow DH. Anxiety Disorders Interview Schedule-Revised (ADISR). Phobia and Anxiety Disorders Clinic, Center for Stress and Anxiety Disorders, State University of New York at Albany, 1988.

24 Dyregrov A, Yule W. Screening Measures-The Development of the UNICEF Screening Battery. Fourth European Conference on Traumatic Stress, 1995.

25 Steinberg MA, Brymer MJ, Decker KB, Pynoos RS. The University of California at Los Angeles Post-traumatic Stress Disorder Reaction Index. Curr Psychiat Rep 2004; 6: 96-100.

26 Qouta S, El-Sarraj E, Punamäki R-L. Mental flexibility as resiliency factor among children exposed to political violence. Int J Psychol 2001; 36: 1-7.

27 Thabet AA, Abed Y, Vostanis P. Comorbidity of PTSD and depression among refugee children during war conflict. J Child Psychol Psychiatry 2004 45: $533-42$

28 Kovacs M. The children's depression inventory (CDI). Psychopharmacol Bull 1985; 21: 995-8.

29 Ghareeb GA, Beshai JA. Arabic version of the children's depression inventory: reliability and validity. J Clin Child Psychol 1989; 18: 323-6.

30 Abdelaziz MT, Mona M. The relationship between PTSD, Anxiety and Depression in Palestinian children with cancer and mental health of mothers. J Psychol Brain Stud 2017; 1: 2-9.

31 Coopersmith S. A method for determining types of self-esteem. J Abnorm Psychol 1959; 59: 87-94.

32 Musa F, Dassouki M. Self-Esteem Inventory for Children. Al-Nahda Publishing Co., 1981.

33 Schaal S, Elbert T. Ten years after the genocide: trauma confrontation and posttraumatic stress in Rwandan adolescents. J Trauma Stress 2006; 19: 95-105.

34 Omona G, Matheson KE. Uganda: stolen children, stolen lives. Lancet 1998; 351: 442.

35 Betancourt TS, Newnham EA, McBain R, Brennan RT. Post-traumatic stress symptoms among former child soldiers in Sierra Leone: follow-up study. Br J Psychiatry 2013; 203: 196-202.

36 Miller T, el-Masri M, Allodi F, Qouta S. Emotional and behavioural problems and trauma exposure of school-age Palestinian children in Gaza: some preliminary findings. Med Confl Surviv 1999; 15: 368-78; discussion 91-3.

37 Tagay S, Ayhan D, Catani C, Schnyder U, Teufel M. The 2014 Yazidi genocide and its effect on Yazidi diaspora. Lancet 2017: 390: 1946.

38 Kizilhan Jl, Noll-Hussong M. Individual, collective, and transgenerational traumatization in the Yazidi. BMC Med 2017: 15: 198

39 Pagotto LF, Mendlowicz MV, Coutinho ES, Figueira I, Luz MP, Araujo AX, et al. The impact of posttraumatic symptoms and comorbid mental disorders on the health-related quality of life in treatment-seeking PTSD patients. Compr Psychiatry 2015; 58: 68-73.

40 Betancourt TS, Borisova I, Williams TP, Meyers-Ohki SE, Rubin-Smith JE, Annan J, et al. Psychosocial adjustment and mental health in former child soldiers-systematic review of the literature and recommendations for future research. J Child Psychol Psychiatry 2013; 54: 17-36.

41 Noll-Hussong M, Glaesmer H, Herberger S, Bernardy K, Schönfeldt-Lecuona C, Lukas A, et al. The grapes of war. Somatoform pain disorder and history of early war traumatization in older people. Z Gerontol Geriatr 2012; 45: 404-10. 